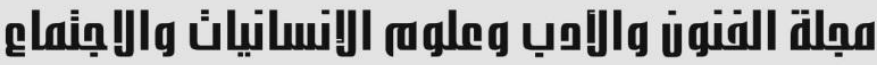

Journal of Arts, Literature, Humanities and Social Sciences

\section{الشعر والسيرة عند الشاعر ولاّه الصوّاف}

\author{
أ.د. ألد. عبد الله حبيب التميمي \\ abdallh.kadhm@qu.edu.iq:الأيميل
}

\section{جنان كعيم غازي الخزاعي alkhazaalijinan@gmail.com : الايميلن}

قسم اللغة العربية ـ كلية التربية - جامعة القادية ـ العراق

توَّسس السيرة في شعر الصوّ اف ذاكرة حرة لا تخضـع لسياقات الو اقع ، فقد جسّد مشرو عه السيري على وفق نسق فني بنوظيف طاقاته الإبداعية وقدر اته الفنية لبلوغ الهدف الذي يرمي إليهه ، فيتستق مع الذاكرة الفرديـة لـه و التاريخيـة لبلاده و التـي يسعى بهـا لبلورة مـا تتطوي عليـه الأبعـاد المكانيـة والزمانيـة في التعبير عن أفكاره ومشاعره ور غباته عبر طر ائق مكللة بمر احل عدة ، لذلك تنوعت أنماطها في شعره إلى (سيرة ذاتية ) و (سيرة غيريّة ) ، تحمل ميثاقاً خيالياً ورؤيّة ذاتية أسهمت في خلق نفيّة سيرية تعبر عن مو اقف وقضايا مرّ بها وعانى منها الشعب ، فتسهم في تسليط الضوء على انفتاح آلية التلقي و البحث عن الذات الثـاعرة. فقد أستطاع الصوّاف أن يستلهم جانباً من سيرته داخل رؤيته لفضاءه السردي التقني بتشغيل خياله الثـعري الذي يقوم على الاحساس

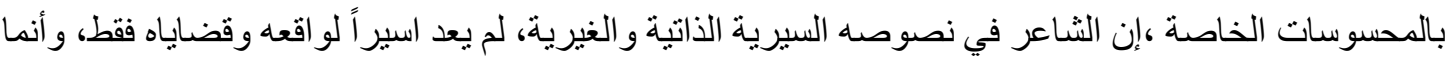
تتحكم الأنا في داخل نسقه السيري من دون أنّ تكثف حجاب البصر فييرز الو اقع الجمعي المهيوم وهو حاضر بـر في كل تفاعلات النفس و الروح منفعلاً بـالفكرة المغلقة وبالحدث الظـاهر و الباطن، فينقل سبرة فكره متعالقة ممتزجة بأزمنة سابقة وحاضرة ومستشرقة للمستقبل. نرى الثـاعر في السيرة الغيريـة التي عمد بها إلى سيرة المدينة وما يحلّ بها من أوجاع و ألم وينعتها بمدينة (بي آر سي) وماحلّ بها من دمار وتخريب وضباع لأبنائها، فيدخل بشفر اتها التاريخية وقد خرج الثناعر بدو افعه ال عقلية في تنظيم سيرة مدينة الحلـة لبعـالق الموقف الحسالي

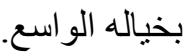




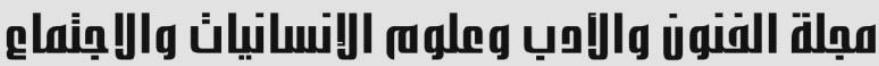 Journal of Arts, Literature, Humanities and Social Sciences www.jalhss.com \\ Poetry and Biography in Walla'a Al- Sawaf
}

\author{
Prof.Dr.Abdallah H. Altememy \\ Emil: abdallh.kadhm@qu.edu.iq \\ Jinan K. GH. Al-Khuzai \\ Emil: alkhazaalijinan@gmail.com \\ Department of Arabic - College of Education -Al-Qadisiayh University -Iraq
}

\begin{abstract}
The biography represents in Al-Sawaf poetry a free memory that is not subject to the rules of the reality. Al-Sawaf's biographical project embodies his creative energies and his artistic abilities to target what he aspires for. Al-Sawaf's biographical representations are consistent with his individual memory as well as the collective memory of his country, which he seeks to crystallize what the spatial and temporal dimensions involve in expressing his ideas. Thus, Al-Sawaf's concepts, feelings and desires are expressed through a number of way methods crowned with several stages. His poetry ranges from "autobiography" to "biography", carrying a fictional covenant and a self-vision that contributed to creating a /n " (auto) biographical" psyche that reflects the situations and issues that he or his people experienced and suffered from. In this way, biography in Al-Sawaf's poetry contributes to highlighting the audience reception for his poetry and accentuating the search for the poetic self. AL-Soaf was able to draw inspiration from his biography within his vision of his technical narrative space by operating his poetic imagination, which is based on a sense of private perceptions, The poet in his personal and altruistic texts, is no longer a prisoner of his reality and his issues only, but the ego controls within its circular pattern without revealing the veil of vision, highlighting the collective collective reality, which is present in all the interactions of the soul and the soul, excited by the closed idea and the apparent and inner event, so it transmits a biography of a related idea Mixed with past, present and recipient. We see the poet in the heterosexual biography with which he baptized into the biography of the city and the pain and pain that befell it in the city (BRC). He enters with her historical codes, and the poet came out with his mental motives in organizing the biography of the city of Hilla to hang the current situation with his wide imagination.
\end{abstract}

Keywords: Poetry, biography, Walla'a Al-Sawaf. 


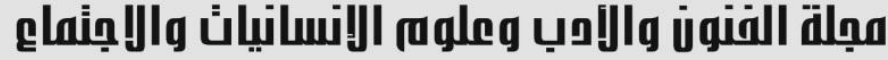

Journal of Arts, Literature, Humanities and Social Sciences

www.jalhss.com

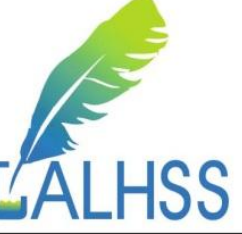

المقدمة

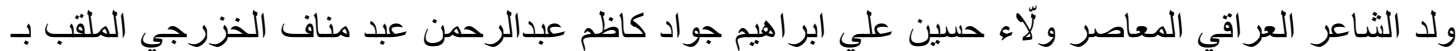

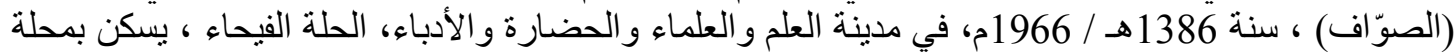

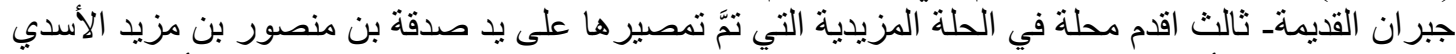

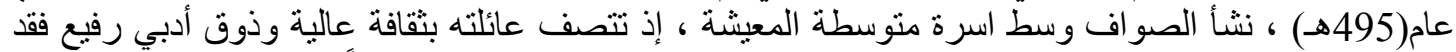

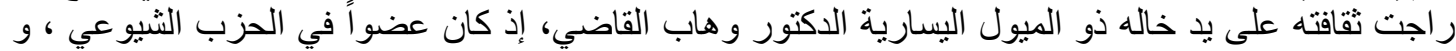

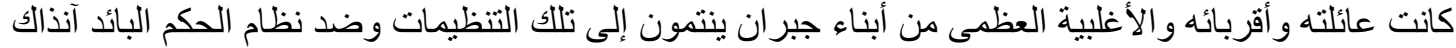

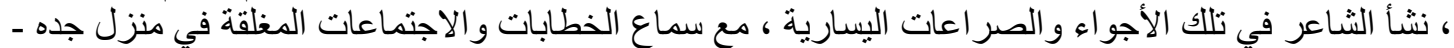

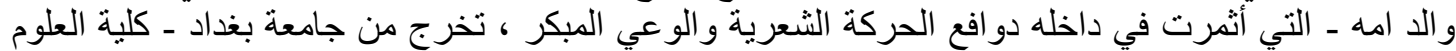

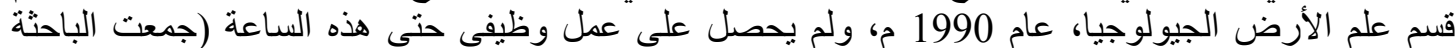

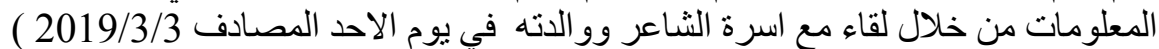

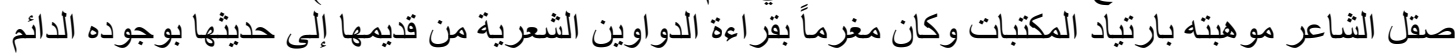

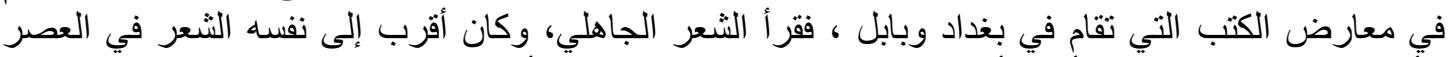

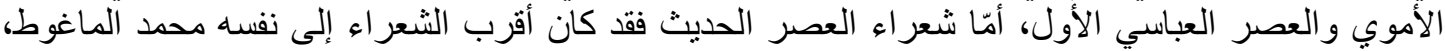

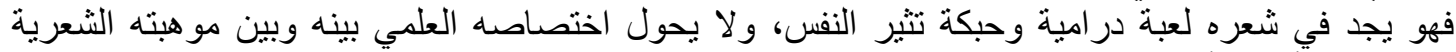

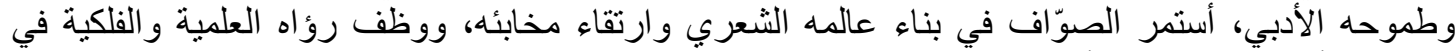

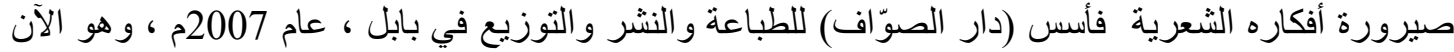

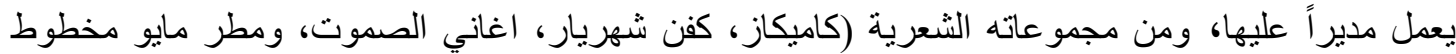

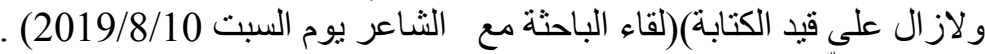

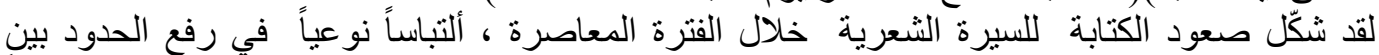

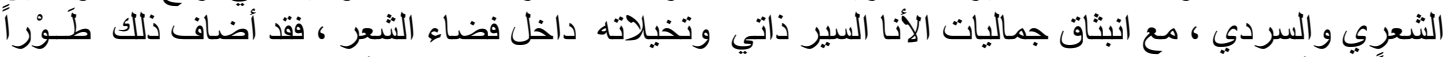

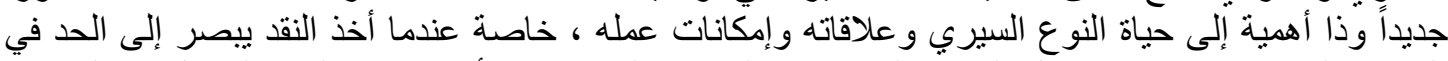

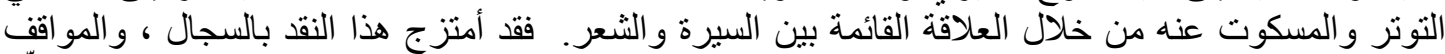

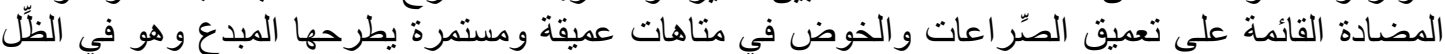

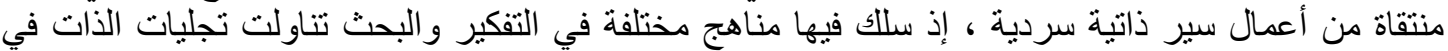

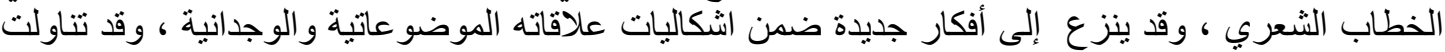

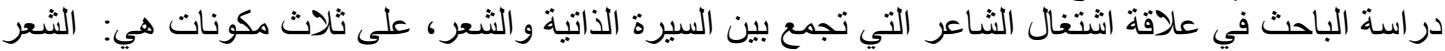

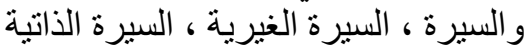

اولا: الشعر والسبرة الشيرة الشيرة

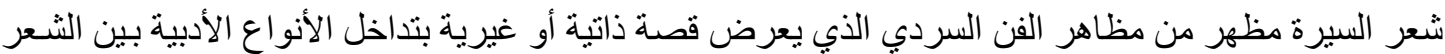

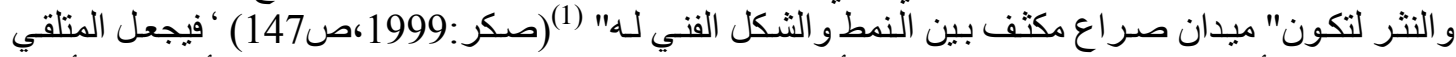

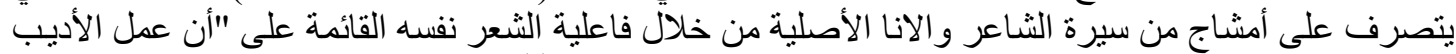

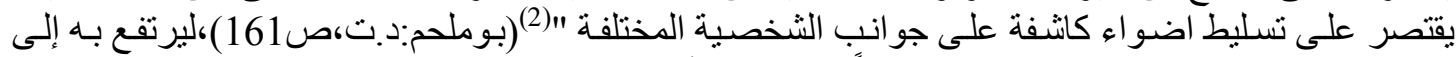

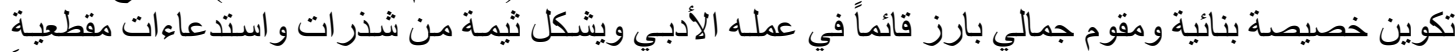

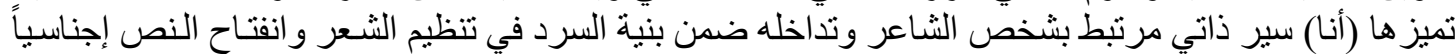

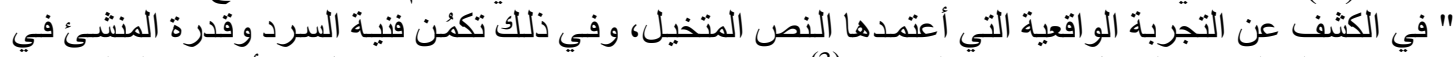

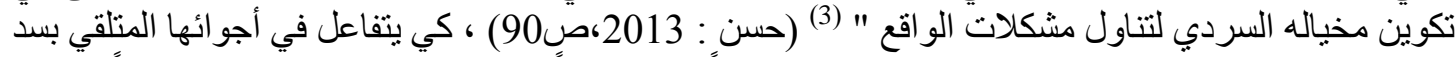

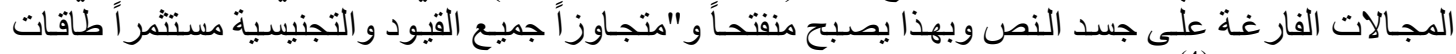

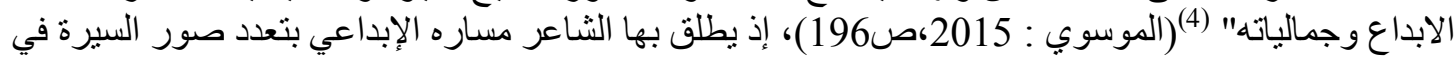

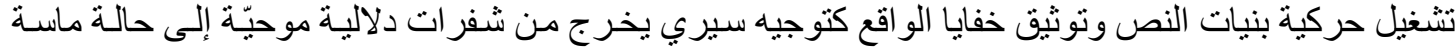




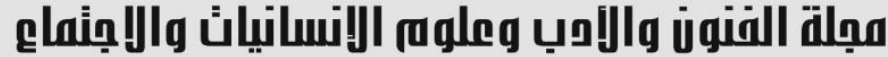

Journal of Arts, Literature, Humanities and Social Sciences

www.jalhss.com

ثانيا: السيرة الغيرية

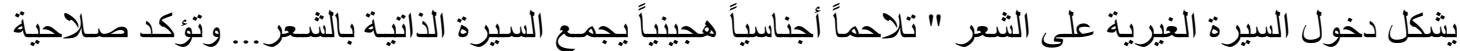

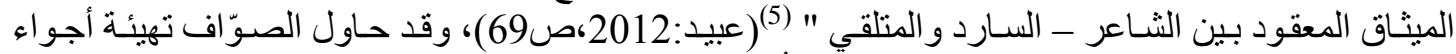

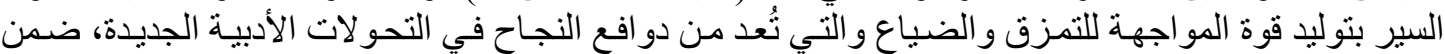

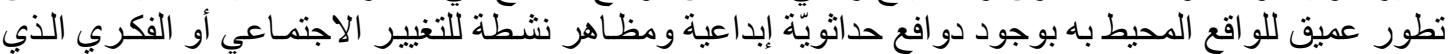

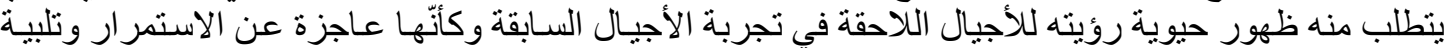

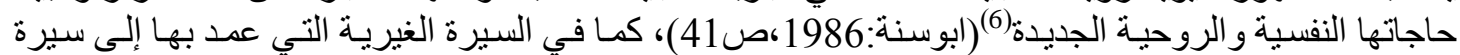

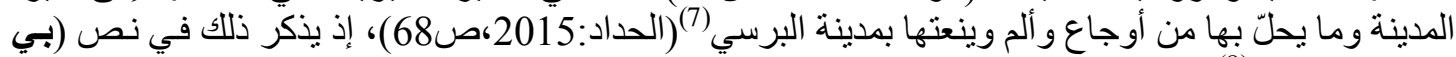

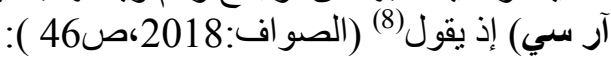

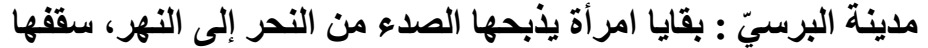

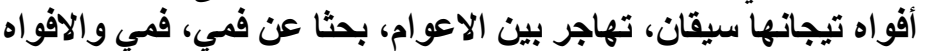

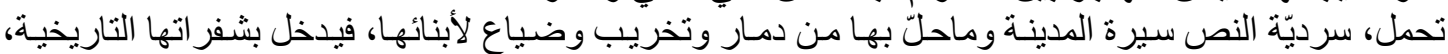

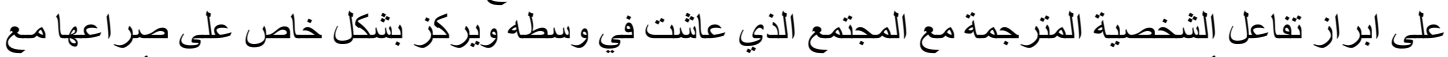

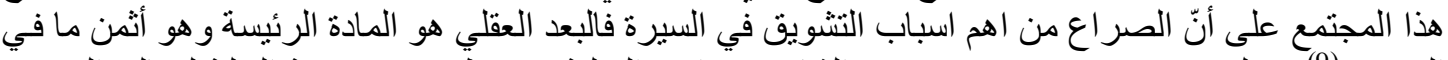

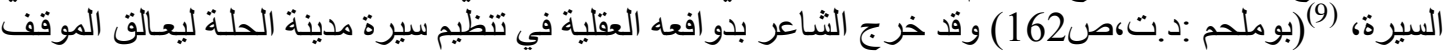

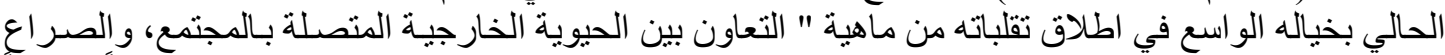

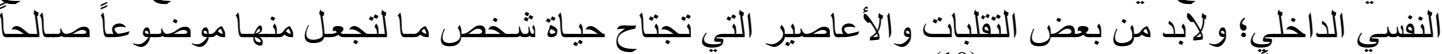

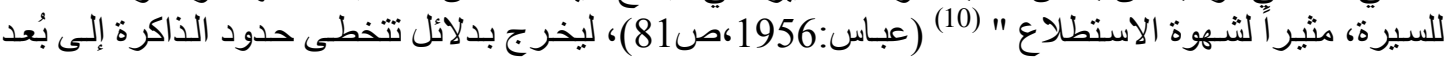

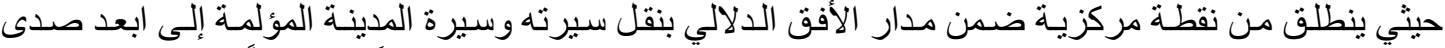

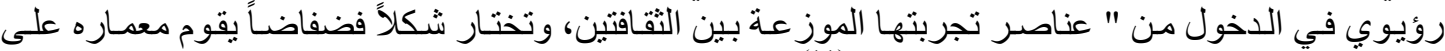

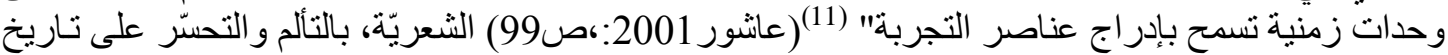

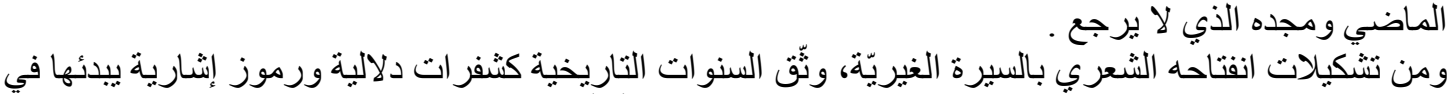

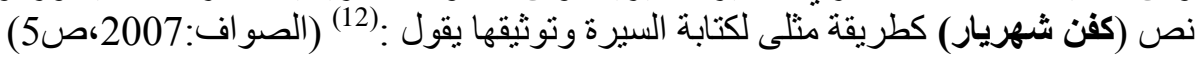

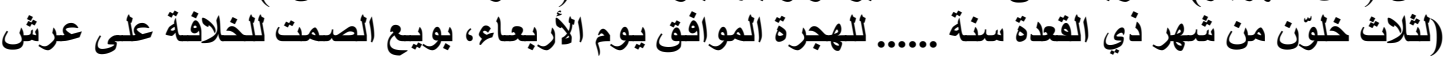

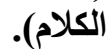
يسردن الثـاعر السيرة، ضمن رؤية تقارب الثكل العنو اني من أجل فتح النص الثعري الحامل لهذه الرؤيـة على الثى

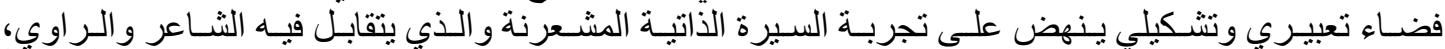

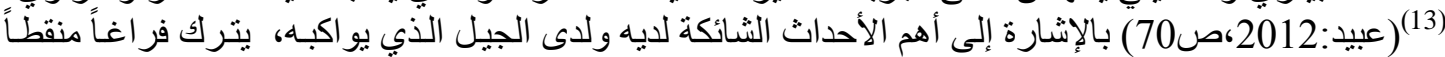

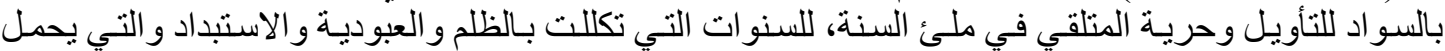

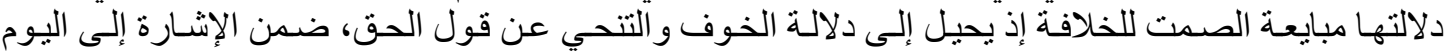

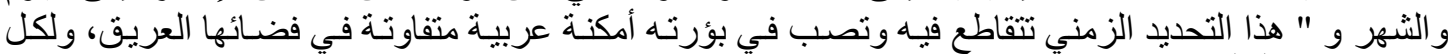

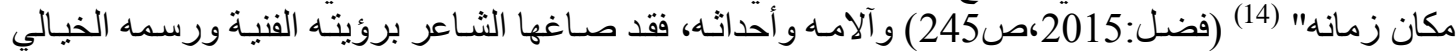

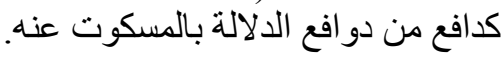

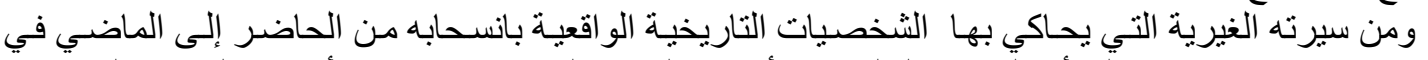

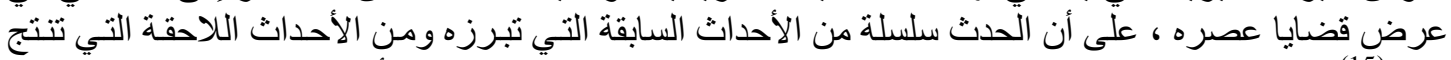

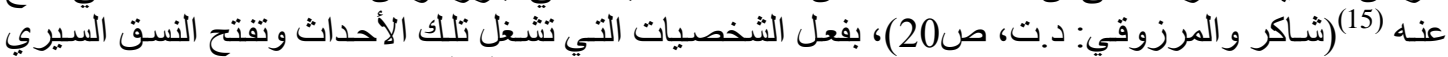

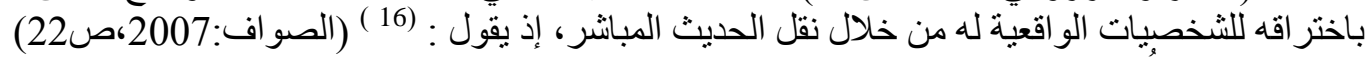

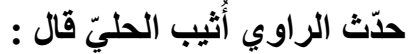

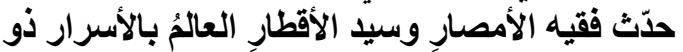

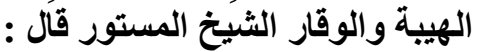

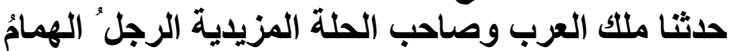
وعلم الأعلام ذُبيسن بن صدقة عن أبيه الأمير صدقة بن الرجن 


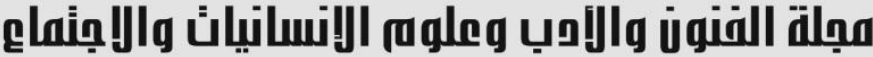 \\ Journal of Arts, Literature, Humanities and Social Sciences}

\section{www.jalhss.com}

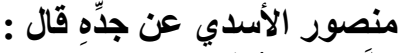

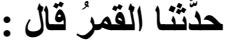
باسم الصمت أبتأ الكلام

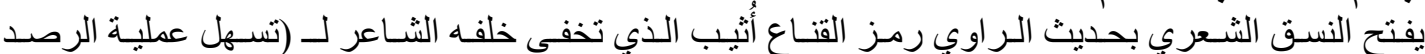

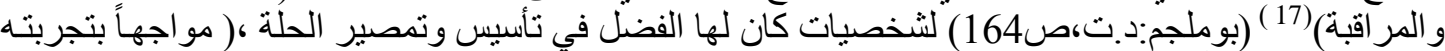

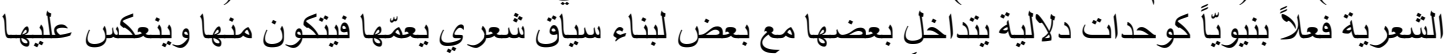

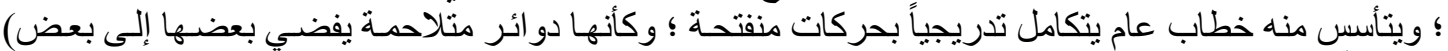

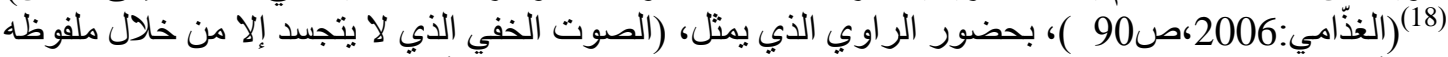

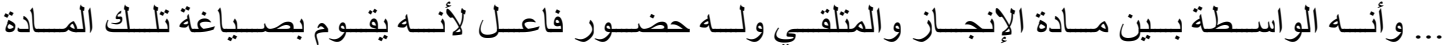

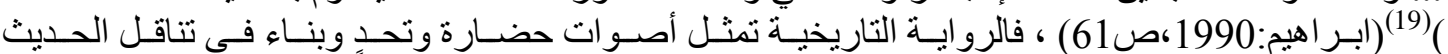

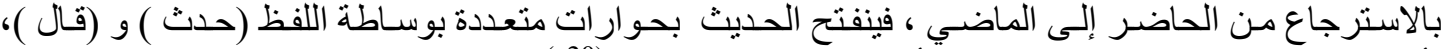

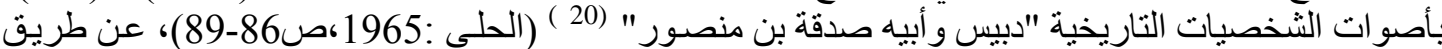

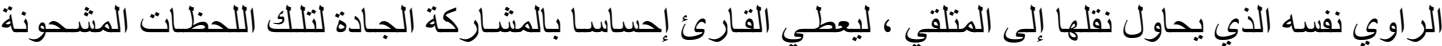

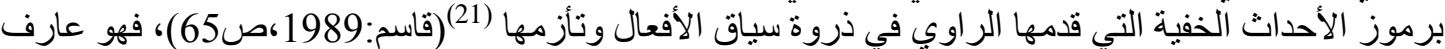

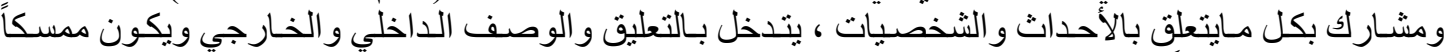

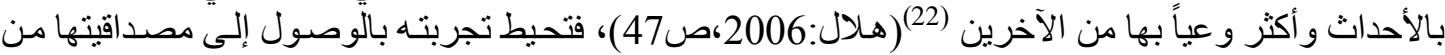

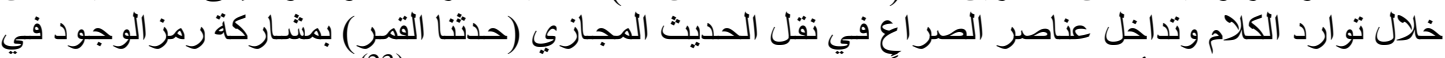

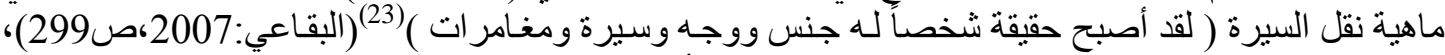

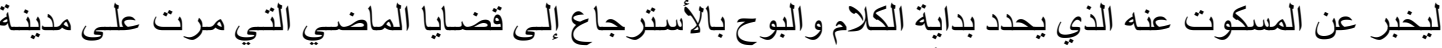

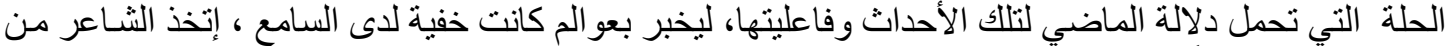

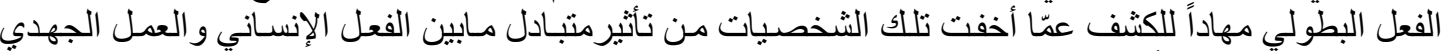
الذي يبدو أثند وضوحاً لللالالة و الإيحاء من خلال كو امنه ولو ازمه الإستعارية .

ويؤطر الثاعر النص السيري بإطار مغلق والإشارة إلى سير قضايا و اقعية متعددة، ضمن أمكنة و أزمنة مختلفة،

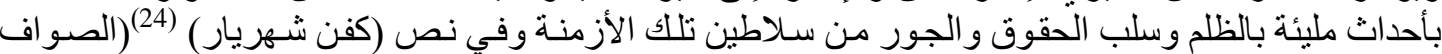

كانت في الأصل سقيفةً واحدةً والآن هي مجموعة سقائف تعود إلى أزمان مختلفةٍة جُددت في الأعوام، 40 هـ، 61 هـ ، 148 هـ، ودخلت اللامرئسي في التاسع من ربيع الأول سنتة 260 هـ 


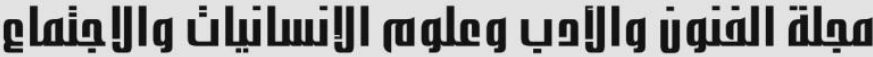

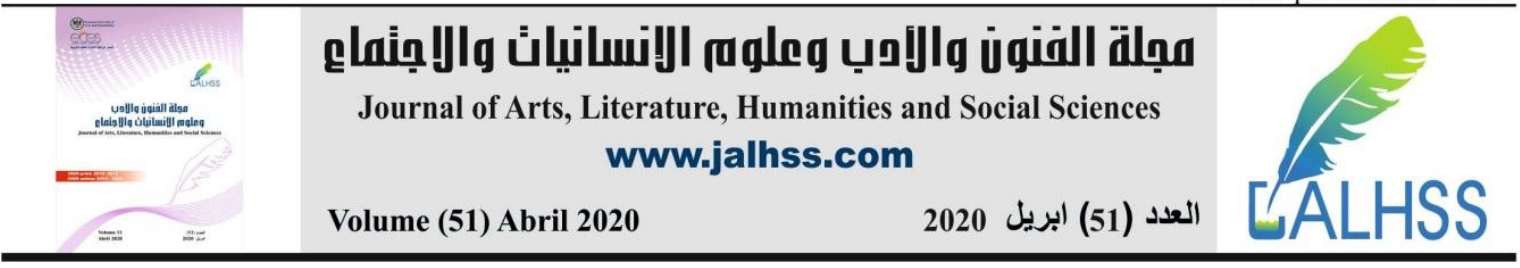

يحصر الأحداث التاريخية التي تصب في منبع و احد لحدث السقيفة وتجديده في كل الأزمنـة فالثـاعر (يرجع إليها

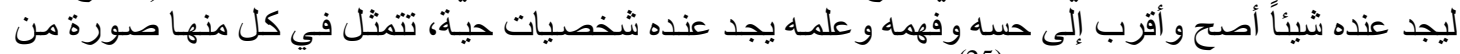

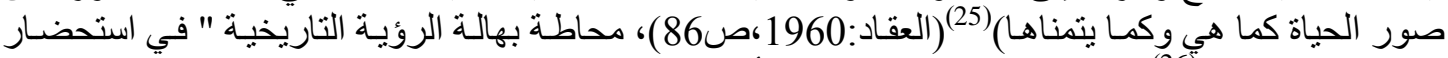

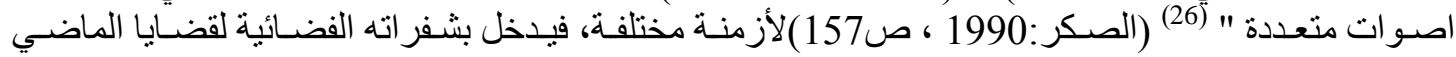

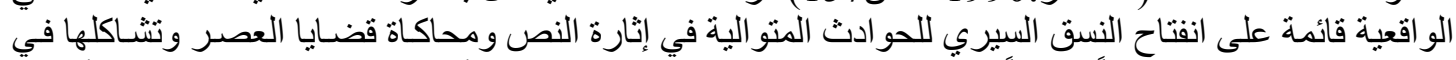

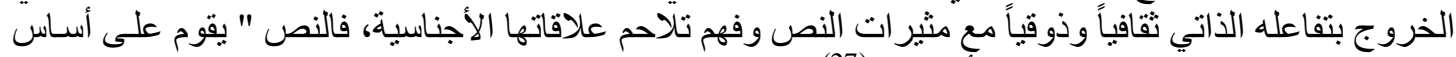

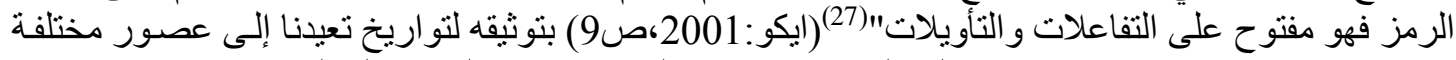

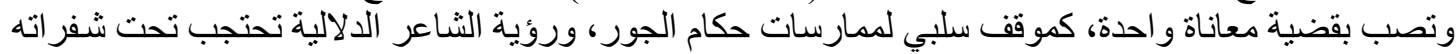

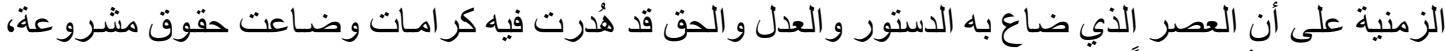

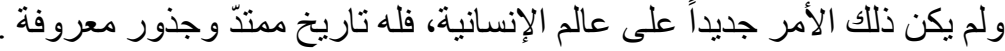

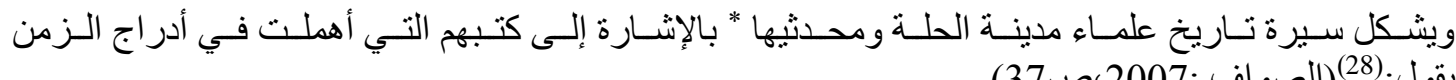

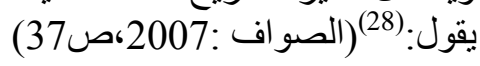

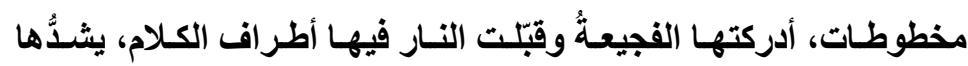

$$
\begin{aligned}
& \text { الحنـينُ إلـى أنامـل النستّـاخ كتـاب، السـرائر لمحمـد بـن إدريس، الألفين } \\
& \text { للعلامة الحليّ، قصائد السبع الطوال للشيخ علي الشفهيني، صوتُ انينٍ } \\
& \text { ينبعث من كتاب الرجال لابن داود }
\end{aligned}
$$

يؤطر النص بمربع كبير في فضاء مغلق بسجن مؤلفات الشخصيات التاريخية دلالة استقصـائها و إهمالها و إهمال

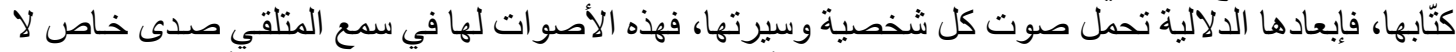

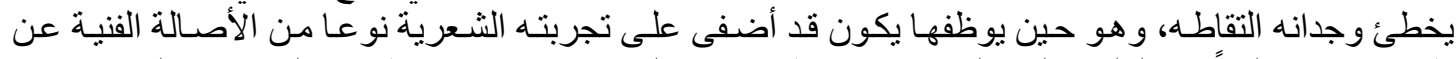

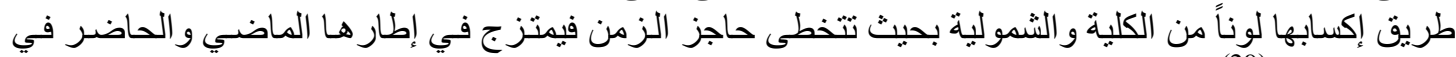

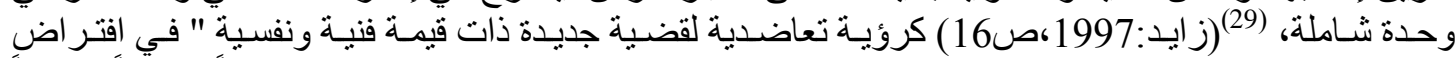

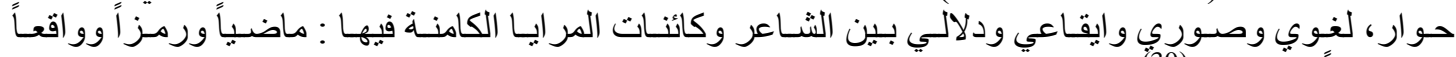

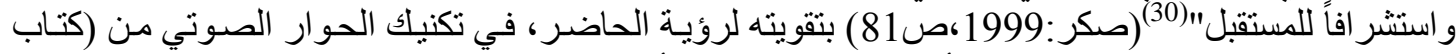

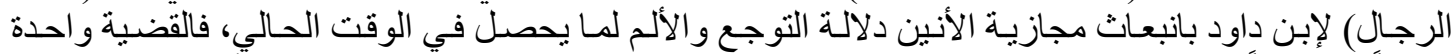

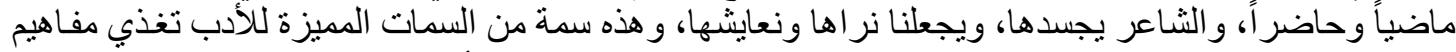

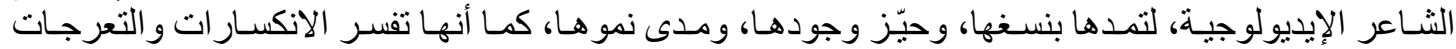

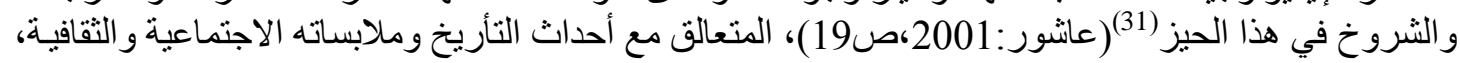
ليعزو بها الثـاعر من حسّ الحنين إلى ذلك التراث آث لاستعادة نشاطه . 


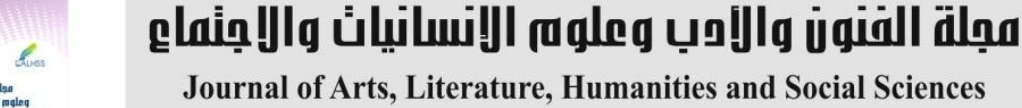

www.jalhss.com

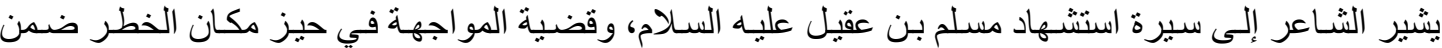

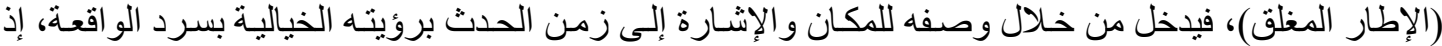

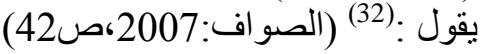

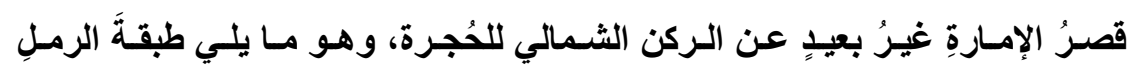
الأبيض، يُمكنُ للراجلِ أن يصلَ إليه قبلَ أن يجفَ الامُ.. أقصد قبل المغيب ..

ما سرُ تحوّل الجسد حين يُقَفَفُ من أعلى سورِ القصرِ إلى ما يُشبهُ زهرة الكاردينيا

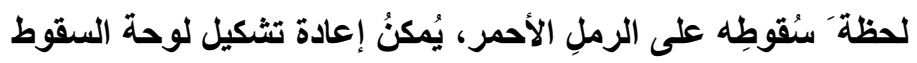

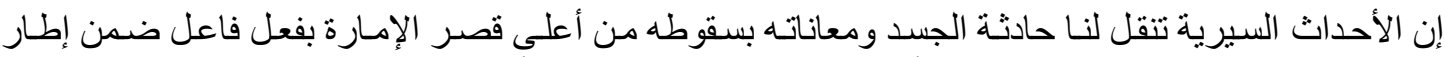

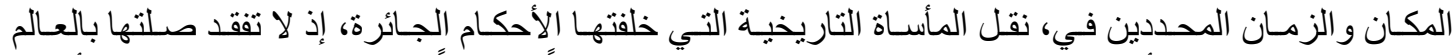

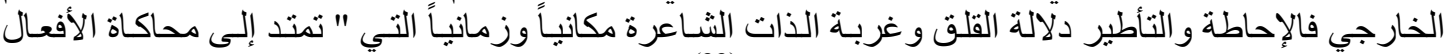

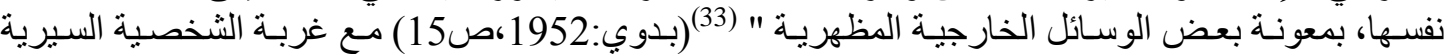

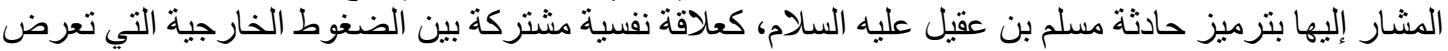

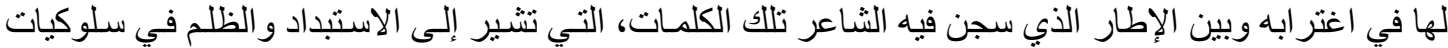

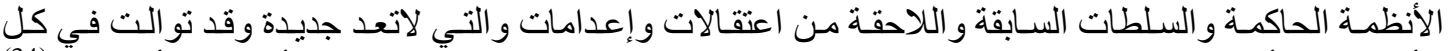

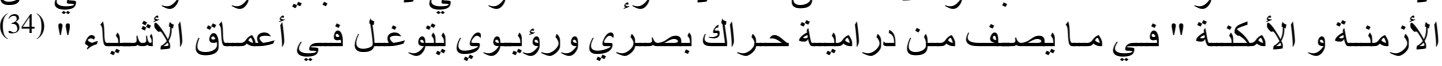

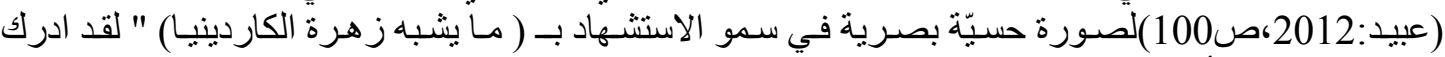

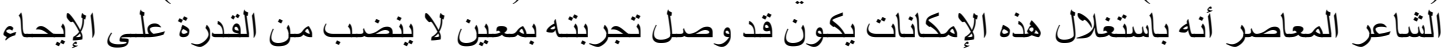

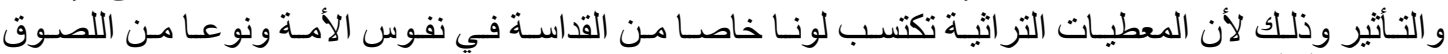

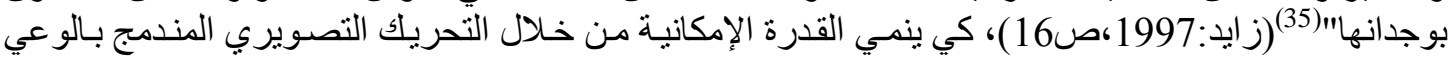

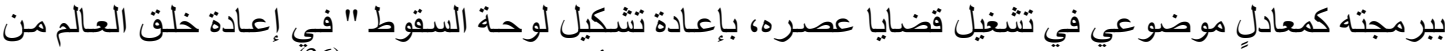

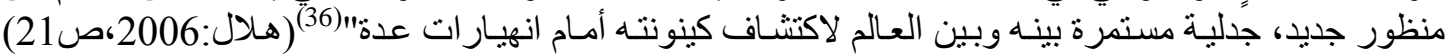
ليحيل النسق إلى ذهن المتلقي في مباثرة الاختز ان الفكري كمعرفة سـابقة لأبعاد النص الثكلية وتأصيل دلالة

تالثا: السيرة الأتية

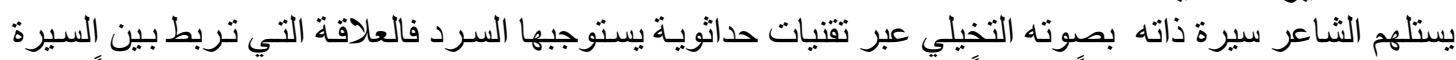

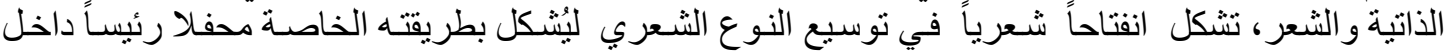

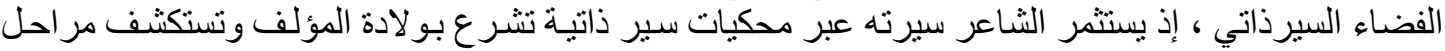

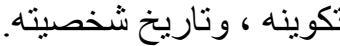

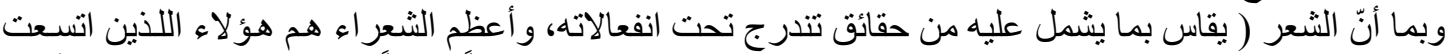

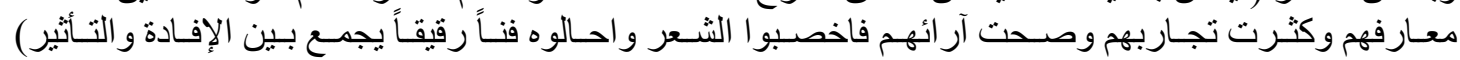




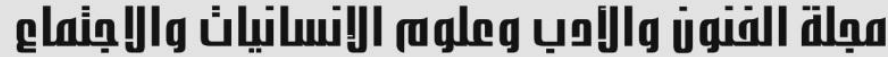 \\ Journal of Arts, Literature, Humanities and Social Sciences www.jalhss.com}

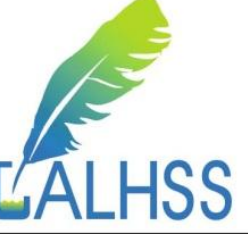

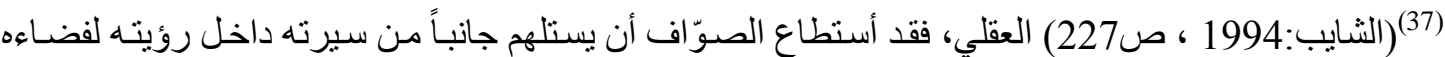

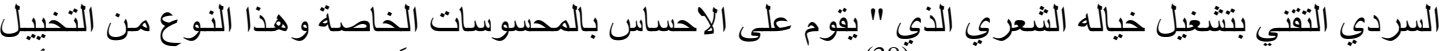

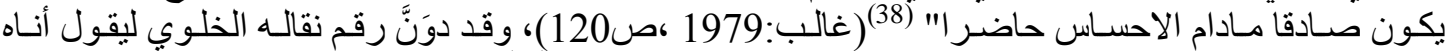

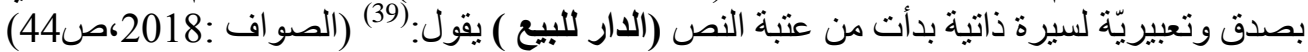

07801168410 : للاتصال

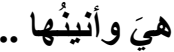

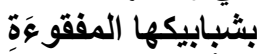

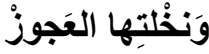

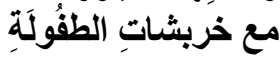

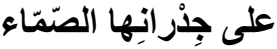

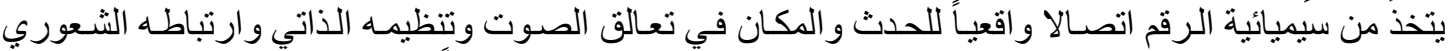

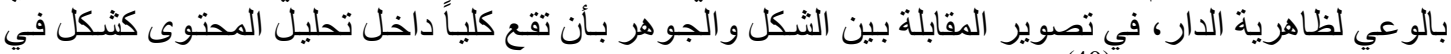

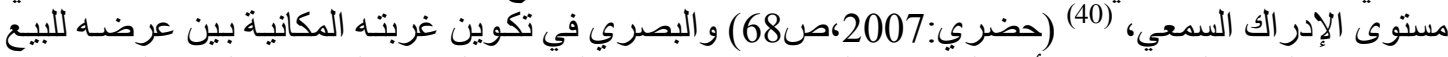

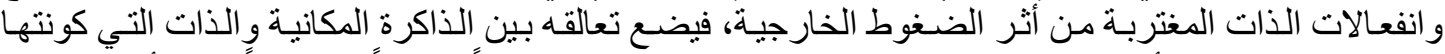

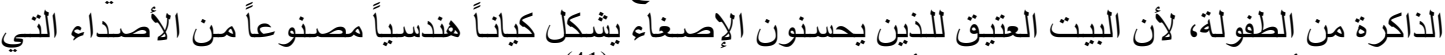

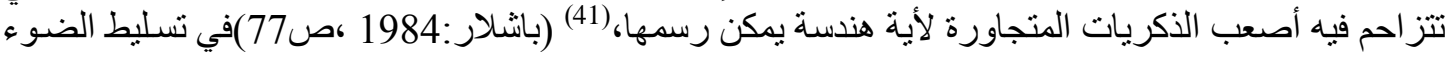

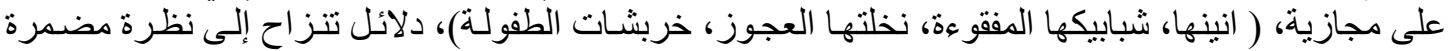

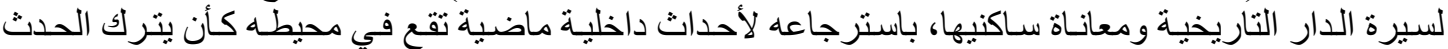

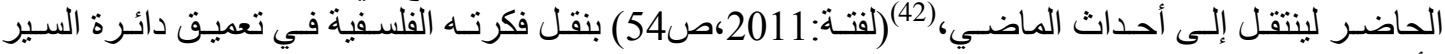

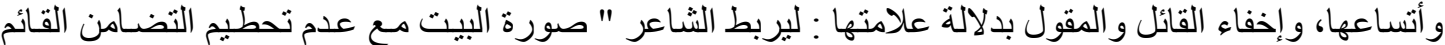

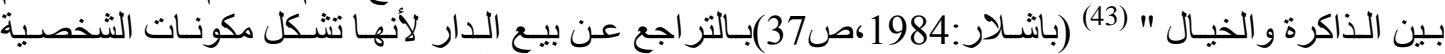

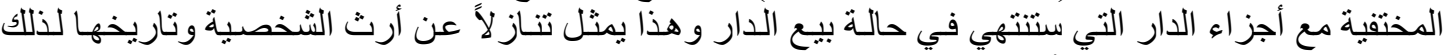

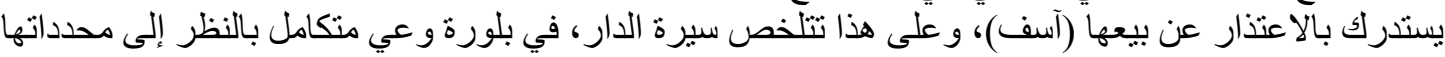

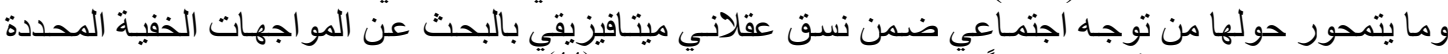

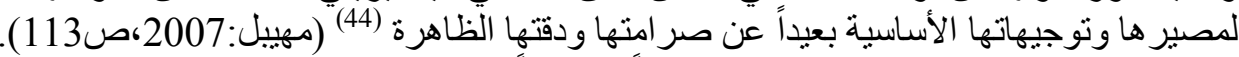

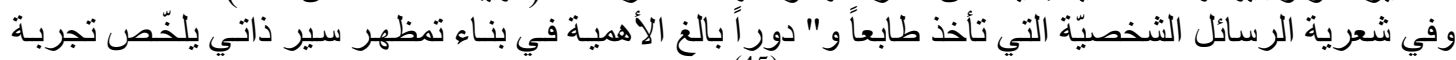

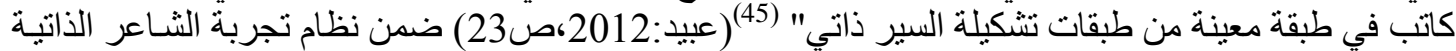
ورؤيته التصويرية الذي يوجه بها إحساسه بالحزن و الصر اع الداخلي، في نص " فحل التوت في بستان العشيرة

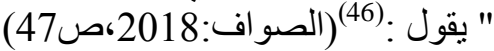

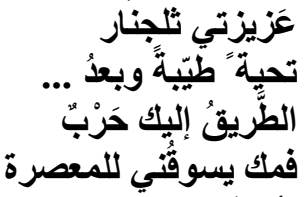

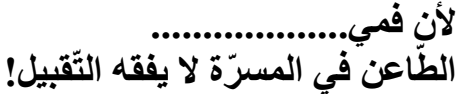

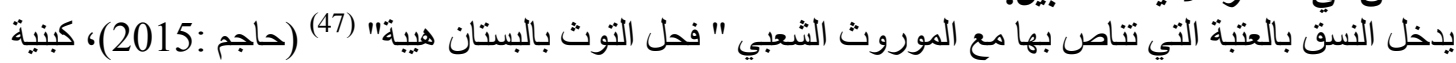

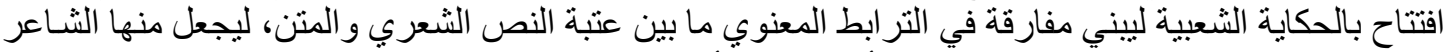

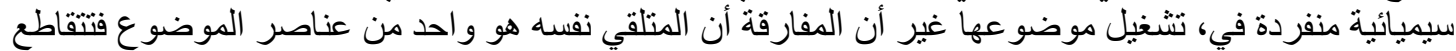

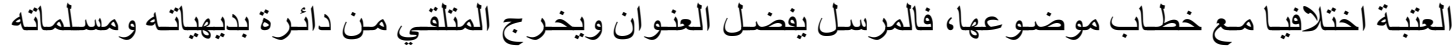




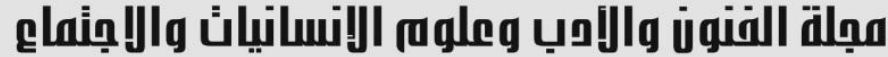

Journal of Arts, Literature, Humanities and Social Sciences

www.jalhss.com

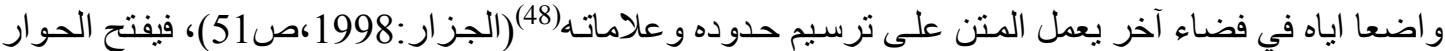

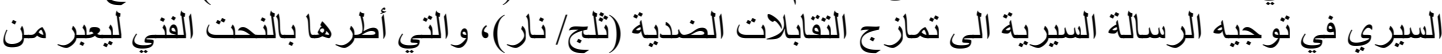

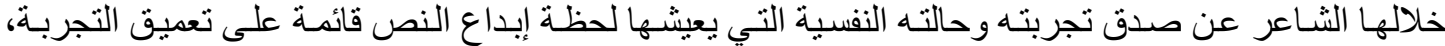

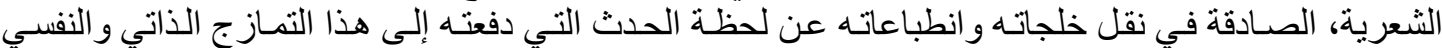

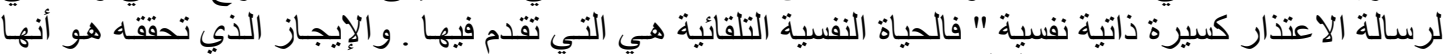

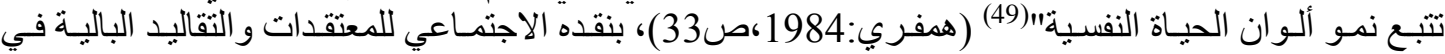

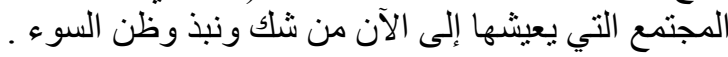

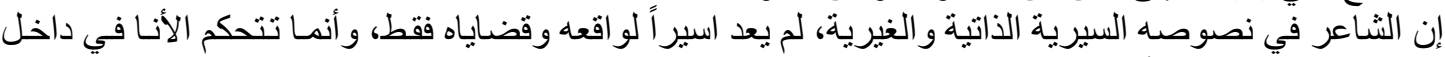

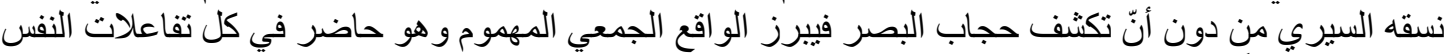

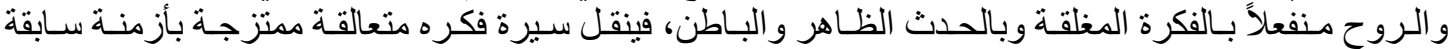

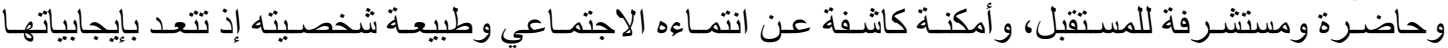

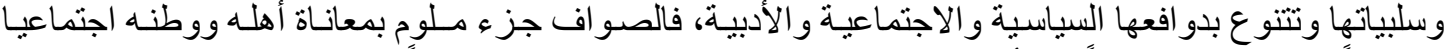

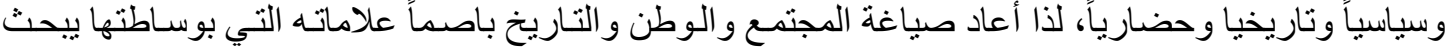

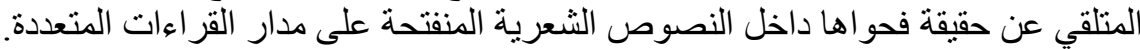

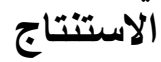

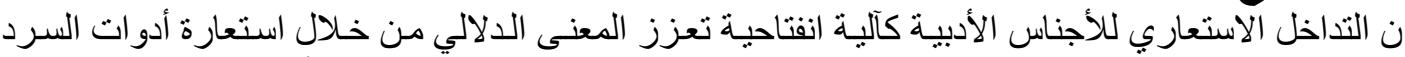

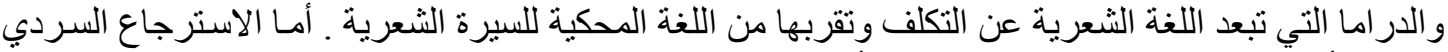

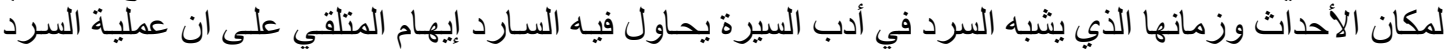

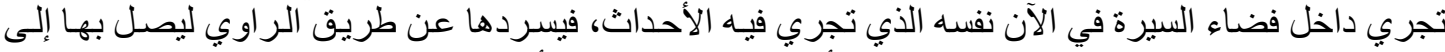

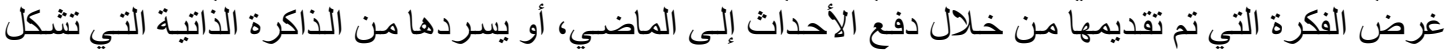

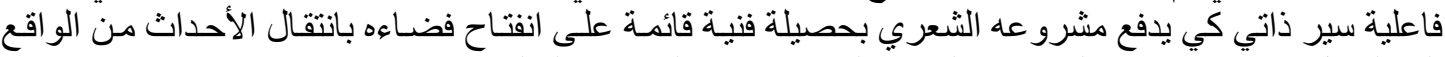
إلى الخيال فيكثَف بها عن المرجعية الثقافية المشتركة بين الثناعر و المتلقي.

الهوامش

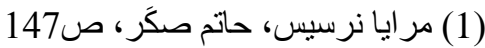

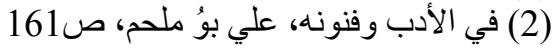

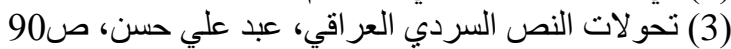

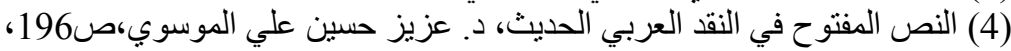

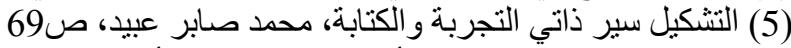

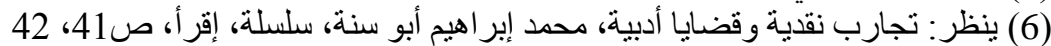

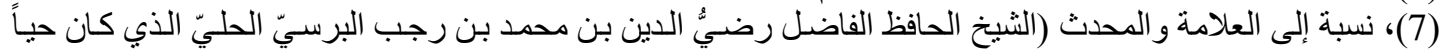

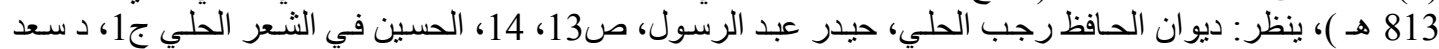

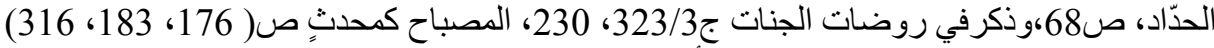

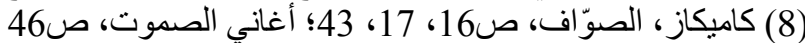

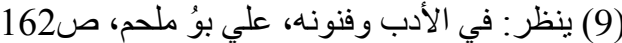

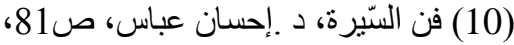

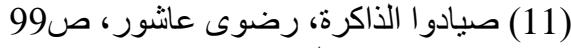

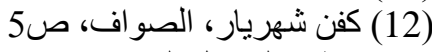

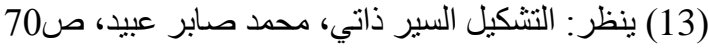

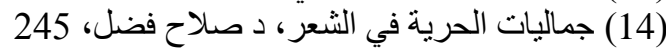

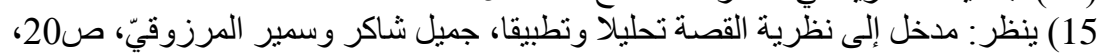

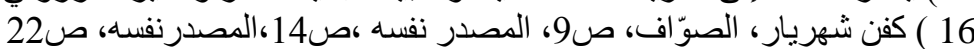

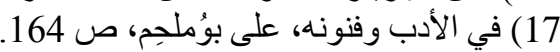




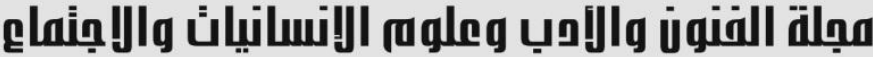

Journal of Arts, Literature, Humanities and Social Sciences

www.jalhss.com

18) تشريح النص: مقاربات تثريحية لنصوص شعرية معاصرة، عبداله الغذّامي، المركز الثقافي العربي، ط2، الدار البيضاء، ص، 89 ، 80 ،

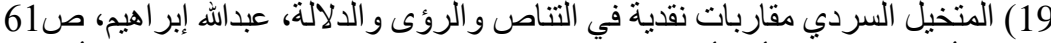

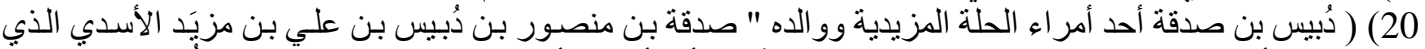

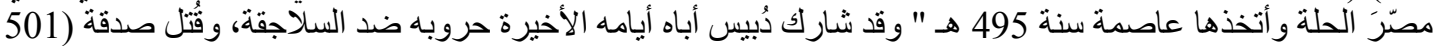

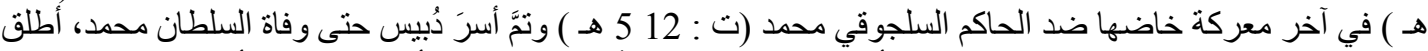

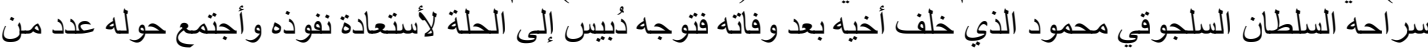

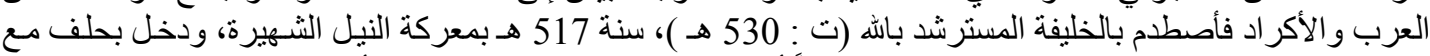

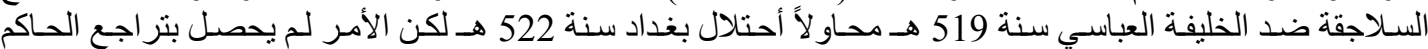

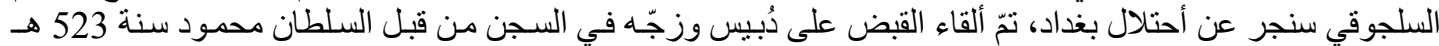

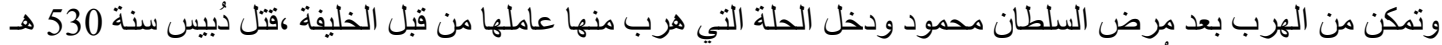

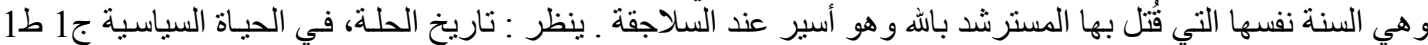

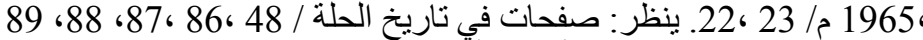

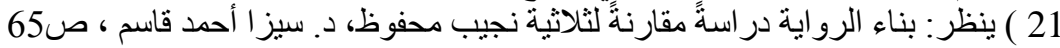

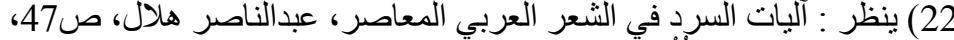

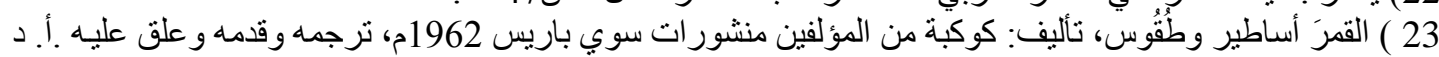

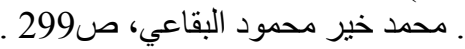

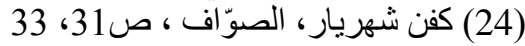

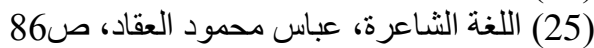

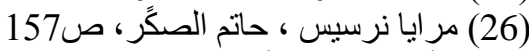

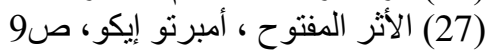

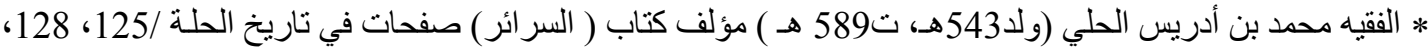

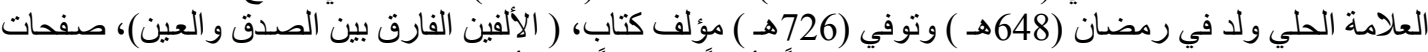

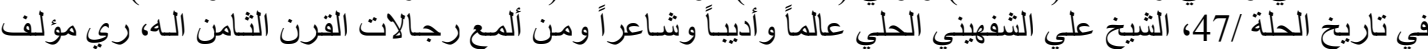

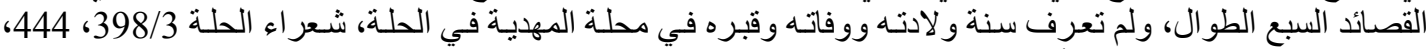

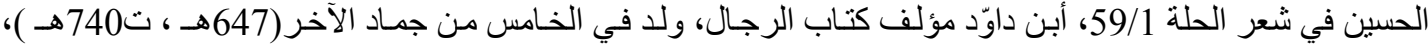

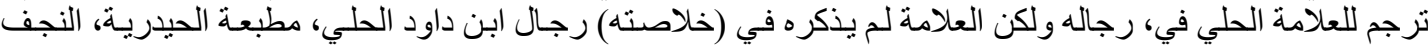

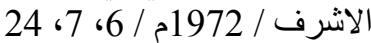

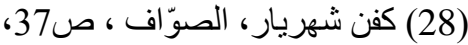

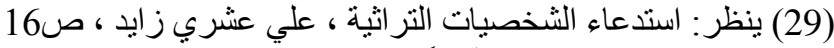

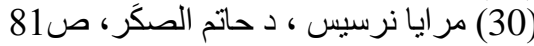

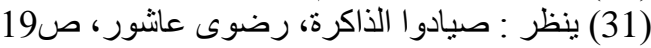

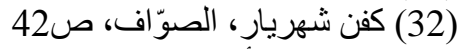

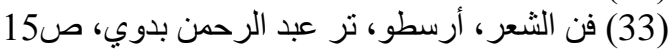

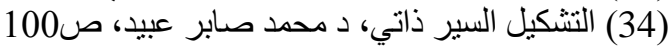

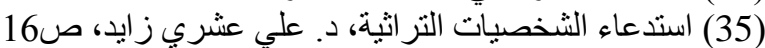

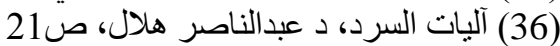

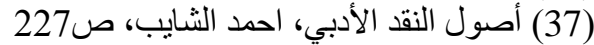

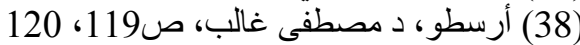

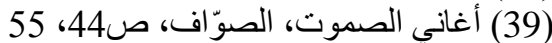

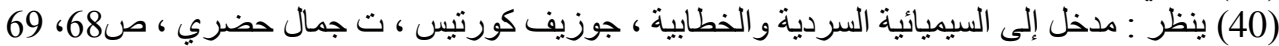

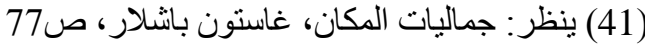

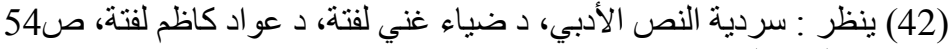

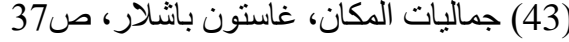

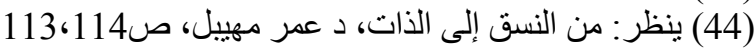

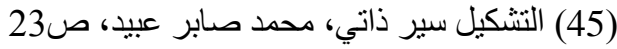




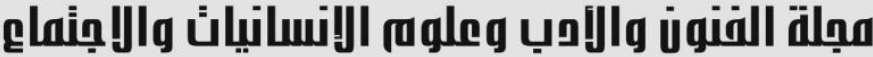

Journal of Arts, Literature, Humanities and Social Sciences

www.jalhss.com

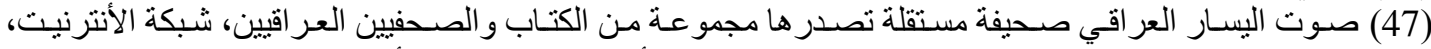

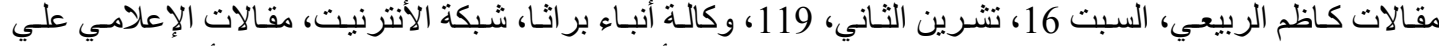

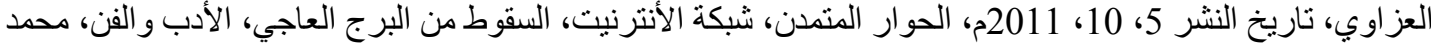

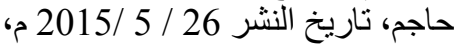

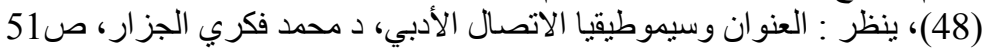

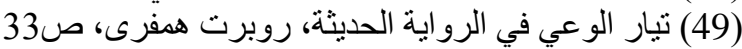

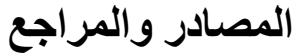 \\ أولاً : المجموعات الثعريّة}

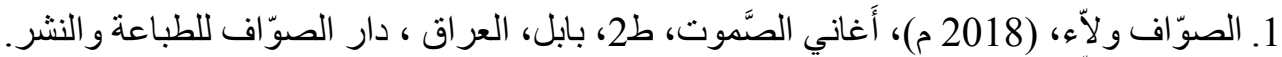

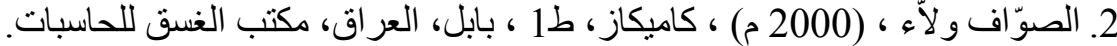

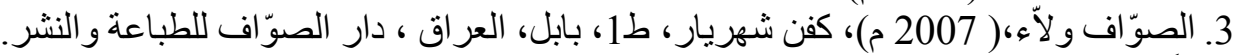
ثانياً: الكتب

1. هـلال عبدالناصـر ، (2 2006 م) ، آليـات السـرد في الثــعر العربـي المعاصـر، ط، القـاهرة، مصـر 1، مركز

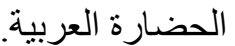

2. أمبرنو إيكو، عبدالرحمن بو علي ، (2001 م) ، الأثر المفتوح، ط2 ، البلاذفيّة، سوريا، دار الحوار للنشر و التوزيع.

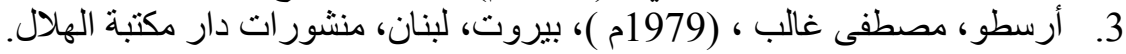

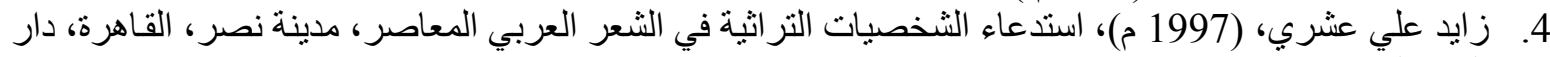
الفكر العربي.

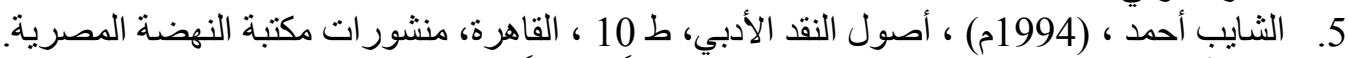

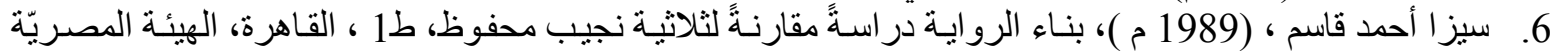
العامة للكتاب. 7. الحلي العلامـة المتتبع الثيخ يوسف كركوش ،(1965 م) ،تاريخ الحلـة في الحياة السياسية ، م 1 ، ط1 ، النجف الأشرف، المبل العبعة الحيدرية.

8.

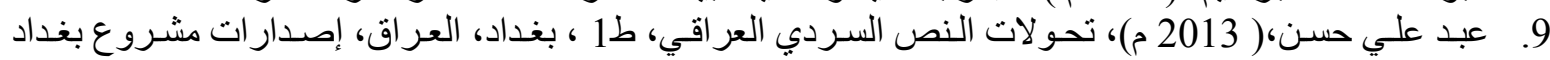
عاصمة الثقافة العربية. 10. محمد صـابر عبيد ، (2 2012 م )، التشكيل سير ذاتي / التجربـة والكتابـة ، دمثق، سوريا، دار نينوى للار اسـات و النشر والتوزيع.

11. همفرى روبرت ، الربيعي محمود ،( 1984 م)، تبار الوعي في الرواية الحديثة ، النبرة، مصر، مكتبة الثباب.

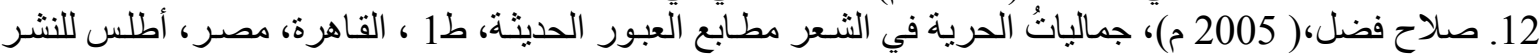
و الإنتاج الإعلامي.

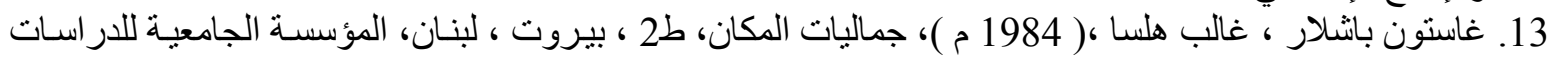
و النشر و التوزيع.

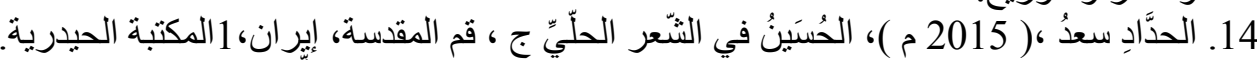

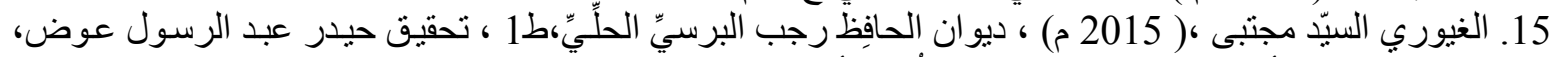

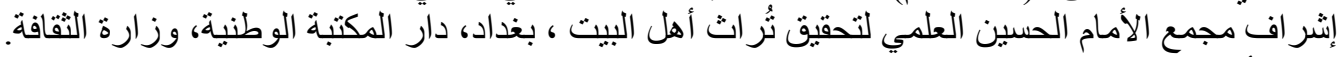

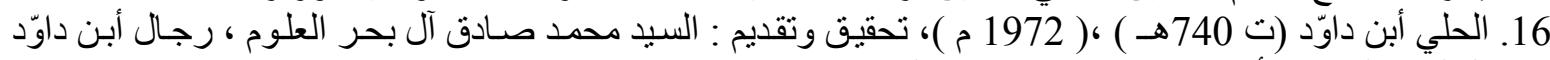

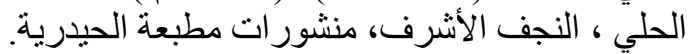




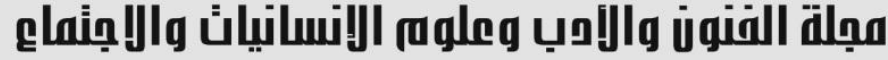

17. الخو انساريّ الأصبهاني العلامـة المتتبع الميرزا محمد بـاقر الموسوي ، (1991 م )، روضـات الجنان في أحوال

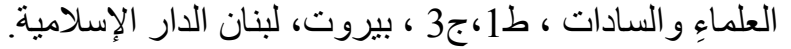

18. الغذامي عبد الله(2006)،تشريح النص مقاربـات تشريحية لنصوص شـعرية ،ط2 ،الدار البيضـاء، مركز الثقافة

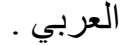

19. ابر اهيم عبداله،(1990)،المتخيل السردي مقاربـات نقديـة في الرؤى والدلالـة ،ط1،الدار البيضـاء، المركز الثقافي العربي.

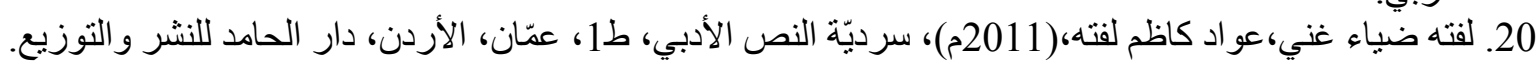

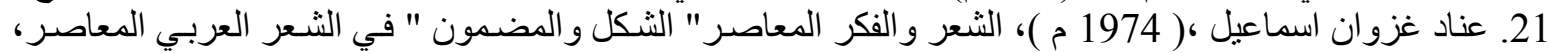

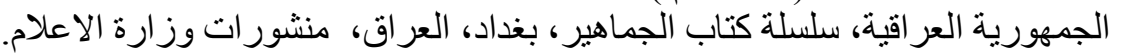

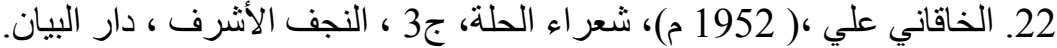

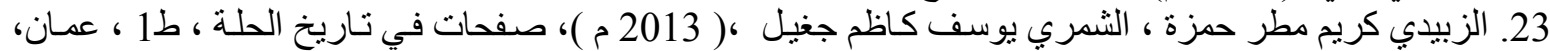
الأردن، دار الرضوان للتوزئ.

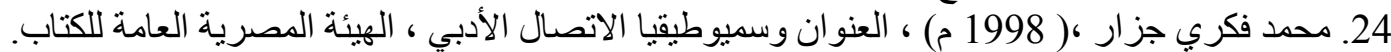

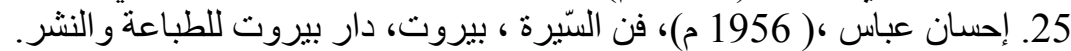

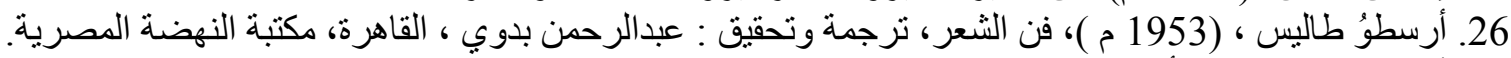

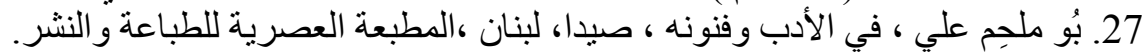

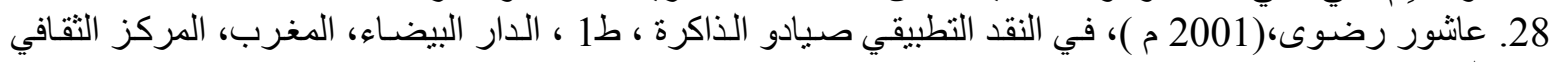
العربي.

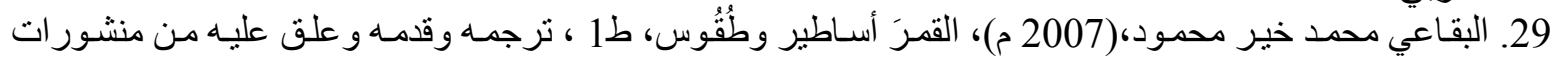

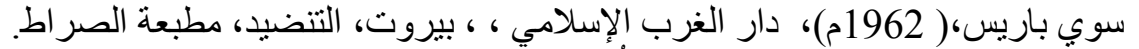

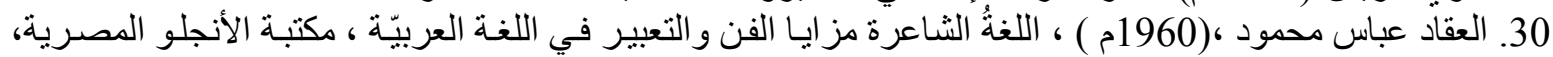

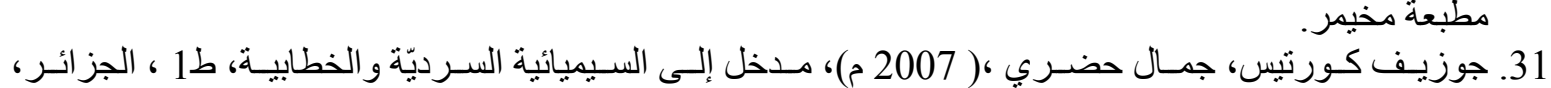
منشور ات الاختلاف.

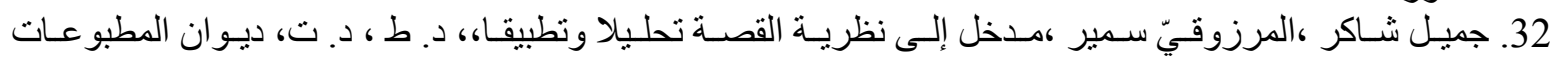

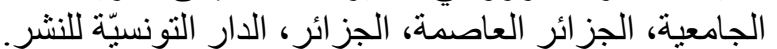

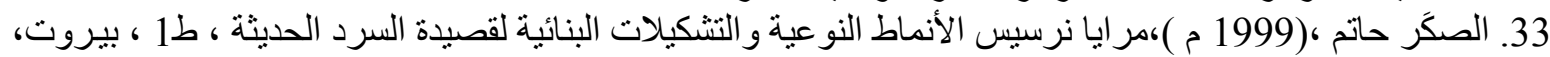

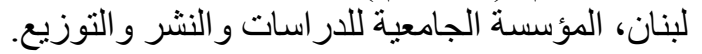

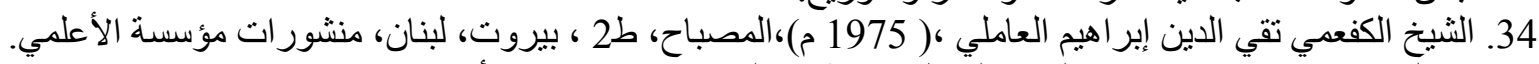

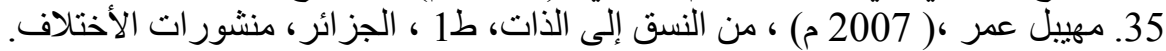

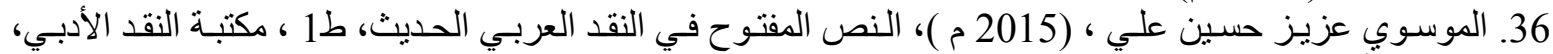
عمان، الأردن، الدار المنهجية للنشر و التوزيع. ثالثاً: شبكة الأنترنيت

1. محمد حاجم،( 2015)،السقوط من البرج العاجي، ع 40918، الحوار المتمدن ، مناح على الر ابط: http://www.ahewar.org/debat/show.art.asp?aid=469705\&nm=1

2. الربيعي كاظم،فحل التوث بالبستان هيبة، صحيفة صوت اليسار العر اقي، مناح على الر ابط: http://saotaliassar.org/Writer/KadumAlrubaiey/FahalAltuth.htm

3. العز اوي علي ، 2011،فحل التوث بالبستان هيبهـ مثلا عر اقيا، وكالة براثا الاعلامية، متاح على الر ابط: http://burathanews.com/arabic/articles/138204 


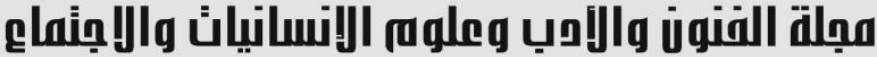

Journal of Arts, Literature, Humanities and Social Sciences

www.jalhss.com

Volume (51) Abril 2020

العدد (51) ابريل 2020

\section{References}

\section{A- Poetic groups}

1. Al-Sawaf Wala ', (2018), Al-Samoot Songs, Print 2nd, Babil, Iraq, Dar Al-Sawaf for Printing and Publishing.

2. Al-Sawaf Wala ', (2000), Kamikaze, Print 1st, Babil, Iraq, Dusk office for computers.

3. Al-Sawaf Wala ',(2007), Shrouriyar Shroud, Print 1st , Babil, Iraq, Dar Al-Sawaf for Printing and Publishing.

\section{B-BOOK}

1. Hilal Abdel Nasser, (2006), Narrative Mechanisms in Contemporary Arab Poetry, 1st edition, Cairo, Egypt, Center for Arab Civilization.

2. Umberto Eco, Abdel Rahman Bou Ali, 2nd edition, (2001), The Open Impact, Lattakia, Syria ,Dar Al-Hiwar Publishing and Distribution.

3. Aristotle, Mostafa Ghaleb, (1979), Beirut, Lebanon, Al-Hila Library Publishing.

4. Zayed Ali Ashry, (1997), Recalling the Heritage People in Contemporary Arabic Poetry, Nasr City, Cairo, Dar Al-Fikr Al-Arabi.

5. Al-Shayeb Ahmed, (1994), The Origins of Literary Criticism, 10th edition, , Cairo Publications of the Egyptian Renaissance Library.

6. Siza Ahmed Qassem, (1989), building the novel, a comparative study of Naguib Mahfouz's trilogy, 1st floor, Cairo, the Egyptian General Book Authority.

7. Al-Hily The Follower, Sheikh Yusuf Karkoush, (1965), History of Hilla, in Political Life, Najaf Al-Ashraf, Al-Haidariyya Press.

8. A Bo Sunnah Muhammad Ibrahim, (1986), Critical Experiences and Literary Issues, Iqra Series, Cairo, Dar Al-Maarif.

9. Abdul Ali Hassan, (2013), Transformations of the Iraqi narrative text, 1st edition, publications of the Baghdad Project, Baghdad, Iraq, the Capital of Arab Culture.

10. Muhammad Sabir Obaid, (2012), Formation Biographies / Experiment and Writing, Nineveh House for Studies, Damascus, Syria, Publishing and Distribution.

11. Humphrey Robert, Al-Rubaie Mahmoud, (1984 ), The Stream of Consciousness in the Modern Novely, Al-Naira, Egypt, Youth Librar.

12. Salah Fadl, (2005), Aesthetics of Freedom in Poetry, Modern Transit Press, 1st edition, Cairo, Egypt ,Atlas for Media Publishing and Production.

13. Gaston Bachelard, Ghalib Helsa, (1984), Aesthetics of Place, 2nd floor, The University Foundation for Studies, Beirut, Lebanon, Publishing and Distribution.

14. Al-Hdad Saad, (2015), Al-Hussain in Sweet Poetry ,Part 1, The Holy Qom, Iran, The Hydrological Library.

15. Al-Ghioury Sayyid Mujtaba, (2015), Al-Hafiz Court, Rajab Al-Persi Al-Halli, 1st edition, Haider Abdul-Rasool Awad investigation, supervised by Al-Imam AlHussein Scientific Complex to achieve the heritage of Ahl al-Bayt, Baghdad ,Dar National Library , Ministry of Culture. 


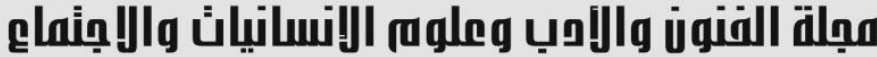

Journal of Arts, Literature, Humanities and Social Sciences

www.jalhss.com

Volume (51) Abril 2020

العدد (51) ابريل 2020

16. Al-Hali Ibn Dawud, (1972), investigation and presentation: Mr. Muhammad Sadiq Al Bahr Al-Ulum, Rijal Ibn Dawood Al-Hilli, Najaf Al-Ashraf, Al-Haydariya Press Publications.

17. Al-Khwansari Al-Asbhani, the follower scholar, Mirza Muhammad Baqir AlMousawi, (1991), Rawdat Al-Jinan in the conditions of scholars and Sadat, 1st edition, part 3, Beirut, Lebanon, the Islamic House.

18. Al-Ghuthami Abdullah (2006), Anatomy of the Text, Anatomical Approaches to Poetic Texts, 2nd Floor, Casablanca, Arab Culture Center.

19. Ibrahim Abdullah, (1990), The Narrative Imagine Critical Approaches to Visions and Significance, 1st Floor, Casablanca, Arab Cultural Center.

20. Dhia Ghani Laftah, Awad Kazem Laftah, (2011), Narrative of the Literary Text, 1st edition, Amman, Jordan, Dar Al-Hamid for Publishing and Distribution.

21. The obstinacy of Ghazwan Ismail,(1974), Contemporary Poetry and Thought "Form and Context" in Contemporary Arab Poetry, Iraqi Republic, Book of the Masses, Baghdad, Iraq, Publications of the Ministry of Information.

22. Al-Khakani Ali, (1952), Poets of Hilla, Vol. 3, Najaf Al-Ashraf, Dar Al-Bayan.

23. Al-Zubaidi Karim Mattar Hamza, Al-Shammari Yousef Kazem Jagil, 1st edition, (2013), pages in the history of Hila, Amman, Jordan, Dar Al-Radwan Distribution.

24. Mohamed Fekry Jazzar, (1998), Title and Sumoytiaqa Literary Communication, the Egyptian General Book Authority.

25. Ihsan Abbas, ( 1956), Biography, Beirut, Beirut Printing and Publishing House.

26.Aristotle Thales, ( 1953), The Art of Poetry, Translation and Verification: Abd alRahman Badawi, Cairo, Egyptian Renaissance Library.

27. Bou Melhem Ali, in Literature and Art, Saida, Lebanon, Modern Printing and Publishing Press.

28. Ashour Radwa,(2001), In Applied Criticism, 1st, edition Memory Hunters, Casablanca, Morocco, Arab Cultural Center

29. Al-Buqai Muhammad Khair Mahmoud,, (2007), The Moon is myths and rituals, 1 st edition, translated, presented and commented on by Sui Paris Publications, (1962 ), Beirut, Al-Sarat Press Dar Al-Gharb Al-Islamiyyat.

30. Al-Aqqad Abbas Mahmoud, (1960), The Poetic Language, The Advantages of Art and Expression in the Arabic Language, Mukhaimir Press, The Anglo-Egyptian Library.

31. Joseph Curtis, Gamal Hadari, 1st edition, (2007), Introduction to Narrative and Rhetorical Semiotics, Algeria, Variation Publications.

32. Jamil Shaker, Al-Marzouki Samir, An Introduction to Story Theory, an analysis and application, University Press, Algiers, Algeria ,Tunisian Publishing House.

33. Al-Sukkar Hatim, (1999), Mirrors of Narcissus, Specific Patterns and Structural Formations of Modern Narration Poem, 1st edition, University Foundation for Studies, Beirut, Lebanon, Publishing and Distribution.

34. Sheikh Al-Qafami Taqiuddin Ibrahim Al-Amili, 2nd edition, (1975), Al-Misbah, Beirut, Lebanon, Publications of Al-Alami Foundation. 


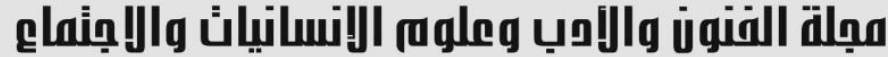

Journal of Arts, Literature, Humanities and Social Sciences

www.jalhss.com

35. Mahibel Omar, (2007), From Layout to Self, 1st edition, Algeria, Al-Akhtafl Publications.

36. Al-Musawi Aziz Hussein Ali, (2015), The Open Text in Modern Arab Criticism, 1st Edition, Literary Criticism Library, Amman, Jordan ,The Methodological House for Publishing and Distribution.

\section{C- Enternet}

1. Muhammad Hajim, , (2015), Falling from the ivory tower, AR 4818,Civilized Dialogue, available at the link:

http://www.ahewar.org/debat/show.art.asp?aid=469705\&nm=1

2. Al-Rubaie Kadhim, Al-Rabat Al-Toth Al-Bostan prestige, The Voice of the Left Iraqi newspaper, available at the following link:

http://saotaliassar.org/Writer/KadumAlrubaiey/FahalAltuth.htm

3. Al-Azzawi Ali, (2011), The Orchard Stallion Heiba - An Iraqi Example, Baratha Media Agency, available at the link:

http://burathanews.com/arabic/articles/138204 